\title{
Prevalence of and factors associated with burnout among health care professionals in Arab countries: a systematic review
}

\author{
I. Elbarazi ${ }^{1}$, T. Loney ${ }^{1}$, S. Yousef ${ }^{2}$ and A. Elias ${ }^{1 *}$ (D)
}

\begin{abstract}
Background: Burnout among healthcare professionals is one of the key challenges affecting health care practice and quality of care. This systematic review aims to (1) estimate the prevalence of burnout among health care professionals (HCP) in Arab countries; and (2) explore individual and work-related factors associated with burnout in this population.

Methods: Multiple electronic databases were searched for studies published in English or Arabic from January 1980 to November 2014 assessing burnout (using the Maslach Burnout Inventory; MBI) amongst health care professionals (HCP) in Arab countries.

Results: Nineteen studies ( $N=4108 ; 49.3 \%$ females) conducted on HCP in Bahrain, Egypt, Jordan, Lebanon, Palestine, Saudi Arabia and Yemen were included in this review. There was a wide range of prevalence estimates for the three MBI subscales, high Emotional Exhaustion (20.0-81.0\%), high Depersonalization (9.2-80.0\%), and low Personal Accomplishment (13.3-85.8\%). Gender, nationality, service duration, working hours, and shift patterns were all significantly associated with burnout.

Conclusions: Within the constraints of the study and the range of quality papers available, our review revealed moderate-to-high estimates of self-reported burnout among HCP in Arab countries that are similar to prevalence estimates in non-Arabic speaking westernized developed countries. In order to develop culturally appropriate interventions, further research using longitudinal designs is needed to confirm the risk factors for burnout in specific HCP settings and specialties in Arab countries.
\end{abstract}

Keywords: Arab World, Compassion Fatigue, Depersonalization, Emotional Exhaustion, Health Personal, Maslach Burnout Inventory, Occupational Health, Personal Accomplishment, Professional Burnout, Wellbeing

\section{Background}

Burnout syndrome is a state of physical, emotional, and mental exhaustion that results from prolonged exposure to job stressors or work situations that are emotionally demanding [1-3]. Burnout can have numerous detrimental ramifications on organizations and individuals, such as increased staff turnover, absenteeism, sickness, injury and accidents, low productivity, and interpersonal and organizational conflicts [4]. Health care professionals (HCP) are at a high risk of developing burnout due to

\footnotetext{
* Correspondence: anzaamin@gmail.com

${ }^{1}$ Institute of Public Health, College of Medicine and Health Sciences, United

Arab Emirates University, Al Ain, PO Box 17666, United Arab Emirates

Full list of author information is available at the end of the article
}

the inherent demands and stress of patient care, long and unsociable shift patterns, and an overall high stress environment. Burnout among HCP is one of the emerging challenges affecting health care systems, patient care, and patient safety around the world. Health care professionals may develop symptoms such as anxiety, irritability, mood swings, insomnia, depression, and a sense of failure as a consequence of burnout [5-9]. These symptoms may ultimately lead to decreased job performance and poor patient care [1, 7]. There have been a number of review studies exploring the prevalence and determinants of burnout in HCP in developed and/or westernized countries from North America, Europe, and Australasia [10-15]. However, 
there is a dearth of reviews focusing on burnout in $\mathrm{HCP}$ in developing and non-western countries in the Arab world.

The Arab world consists of 22 countries that are members of the Arab League distributed over two geographical regions Asia and Africa which include Algeria, Bahrain, Comoros, Djibouti, Egypt, Iraq, Jordan, Kuwait, Lebanon, Libya, Mauritania, Morocco, Oman, Palestine territories (Gaza strip and West Bank), Qatar, Saudi Arabia, Somalia, Sudan, Syria, Tunisia, United Arab Emirates, and Yemen [16]. Although some of the Gulf countries are considered high-income countries, all 22 Arab countries are classified as developing countries based on international indicators. The prevalence of burnout may be higher among HCP in Arab countries as their health systems and financing models are either weak, overburdened, or rapidly developing and responding to the changing disease patterns and health status of the population [17]. Many of these countries have a critical shortage of HCP, particularly in some specialties, which may lead to overloading them with work responsibilities and making them prone to burnout. Countries like Iraq, the Palestine territories, Syria, and Yemen have experienced serious deterioration in health care equity and service provision, and also health status due to recent or ongoing civil conflict. The aim of this systematic review was to estimate the prevalence of burnout and explore the factors associated with burnout amongst HCP in Arab countries.

\section{Methods}

This paper has been written in accordance with the Preferred Reporting Items for Systematic reviews and MetaAnalyses (PRISMA) guidelines [18].

\section{Study design}

A systematic review was conducted on studies of burnout prevalence among HCP in Arab countries according to the PRISMA guidelines.

\section{Eligibility criteria}

Studies were included if they: (1) were published in English or Arabic between January 1980 and November 2014; (2) used the Maslach Burnout Inventory (MBI) to measure burnout; and (3) sampled a population of HCP from an Arab country. Studies that did not meet all three criteria were excluded.

\section{Information sources and literature search}

The following electronic databases were searched: PubMed, Science Direct, MEDLINE, Psych INFO, Informit, and ProQuest. References lists of each retrieved paper were searched manually for additional studies.
The Public Health in the Arab World (PHAW) database was also searched manually and an email was sent through the PHAW email list to search for any unpublished studies (gray literature) or papers that were not published in indexed journals. Other websites such as the World Health Organization-Regional Office for the Eastern Mediterranean (WHO-EMRO) website, occupational health and mental health websites were also searched manually for possible papers. A manual search by the authors' name of all retrieved studies to identify additional studies was also conducted. The literature search was last updated on 20 November 2014. A combination of MeSH search terms and keywords were used as follows: 'burnout' 'professional burnout', 'health personnel' or 'health care professionals', 'Arab world' or 'Arabic countries', 'nurses', 'physicians' and 'occupational stress' 'doctors', 'nurses', 'allied health personnel,' 'Middle East', 'Arab countries', 'Middle East and North Africa region', 'Gulf countries' and 'Eastern Mediterranean countries' (see Additional file 1).

\section{Study selection}

Two authors independently screened the titles and abstracts of identified studies and duplicates were removed. Studies considered eligible for full text screening were retrieved for full review.

\section{Data collection process and data items}

Data extracted from each paper satisfying the inclusion criteria was entered into a summary table in the following categories: Authors, Year of Publication, Country, Sample size, Response rate (\%), Gender, Professional Group, Individual and Workplace Factors, Prevalence of High EE (\%), Prevalence of High DP (\%), and Prevalence of Low PA (\%). In the current review, prevalence of each dimension of burnout was assessed in each study. No ethical approval was required as the systematic review is based on published data.

\section{Risk of bias in individual studies}

A modified 15-item checklist developed by STrengthening the Reporting of OBservational studies in Epidemiology (STROBE) [19] was used to evaluate the quality of papers reviewed. Three reviewers independently assessed the papers for eligibility and quality, and then met to resolve any disagreements regarding eligibility and/or quality.

\section{Summary measures}

The Maslach Burnout Inventory (MBI) originally developed by Maslach et al. is a standardized tool used by $90 \%$ of empirical research to measure burnout $[4,20]$. Psychometric analyses conducted on the MBI has shown that the scale has both high reliability and validity 
(convergent and discriminant) as a measure of burnout [21]. Maslach and colleagues identified three scales that can determine burnout syndrome among professionals that include: Depersonalization (DP), Emotional Exhaustion (EE) and a sense of low Personal Accomplishment (PA) [2]. The MBI instrument contains 22 items that measure the cumulative effects of work-related pressure in three subscales: the EE subscale assesses feelings of being emotionally overextended and exhausted by one's work (e.g., intense emotional tiredness); the DP subscale measures a negative, cynical, and impersonal attitude towards recipients of one's service, care, treatment or instruction (e.g., patients); and the PA subscale assesses feelings of competence and successful achievement in one's work with low personal accomplishment corresponding to demotivation, loss of self-confidence, and self-depreciation in relation to work. Each question is assessed on a scale ranging from 0 (not at all) to 5 (yes, absolutely). A high degree of burnout is represented by high scores of EE $(\geq 27)$ and DP $(\geq 13)$ and a low score of PA $(\leq 31)$ [2]. As such, the principal summary measure was the prevalence of burnout assessed by the MBI on the three subscales: EE, DP, and PA.

\section{Risk of bias across studies}

The gray literature and proceedings of related conferences were searched to minimize publication bias and articles in both English and Arabic were eligible to minimize language bias.

\section{Results}

The PRISMA flowchart summarizing the data collection process is presented in Fig. 1. We identified a total of 190 articles during the initial search. Ineligible and duplicate studies were removed and 19 papers from eight countries were included in the final review as they satisfied the inclusion criteria. Included studies consisted of seven papers from Saudi Arabia, three papers respectively from Lebanon, Palestine and Egypt, and one paper each from Jordan, Yemen, and Bahrain. The key information from the included studies is summarized in Table 1. All papers except for one were published in indexed journals and the $\mathrm{HCP}$ in the reviewed papers included doctors, nurses, physiotherapists, social workers, and occupational therapists.

All the included papers were cross-sectional studies with the majority employing a convenient sampling method. The study sample size varied from 37 to 755 with a response rate ranging from 58.0 to $100.0 \%$. A total of $4108 \mathrm{HCP}$ were included in the review. The majority of the studies involved doctors $(N=2169)$ from various departments and specialties; 518 primary healthcare and family physicians; 475 medical residents, 90 pediatricians, 68 anesthesiologists, 69 orthopedic surgeons, and the rest were distributed among other specialties. Nurses ranked second with a total number of 1135 from different specialties, followed by social workers $(N=$ $356)$, emergency responders $(N=140)$, physiotherapists $(N=119)$, occupational therapists $(N=14)$, and the

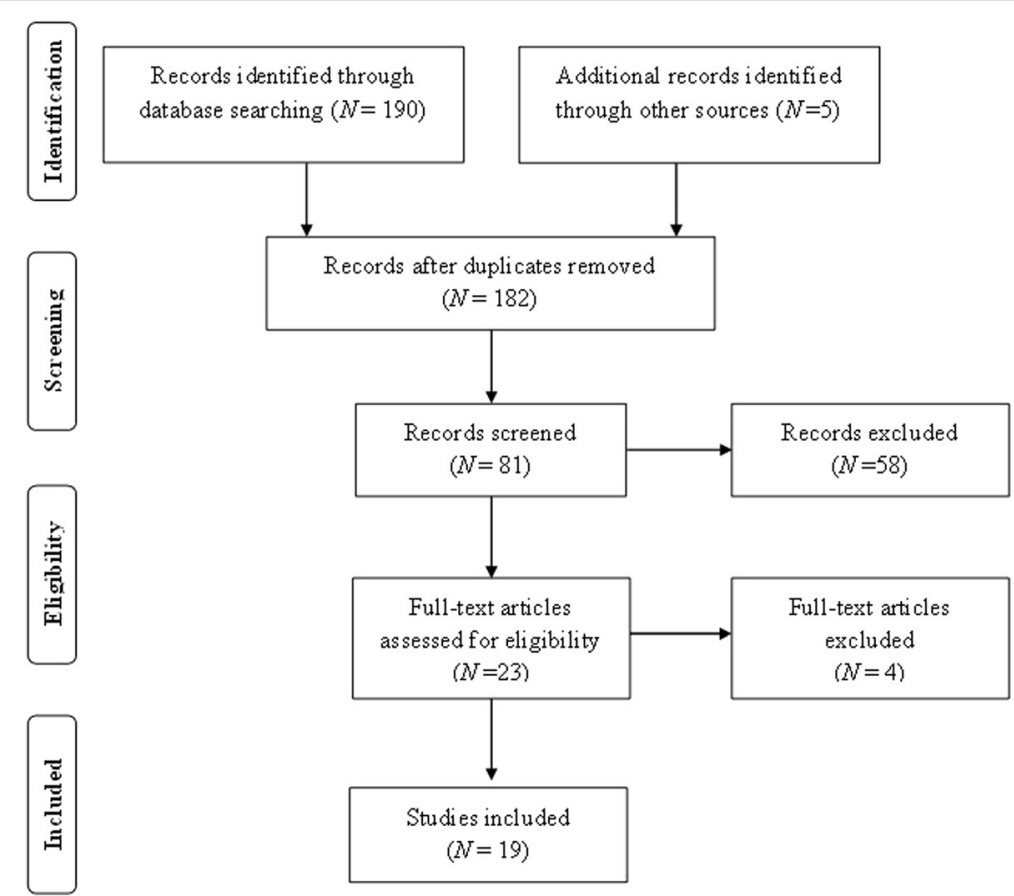

Fig. 1 Flow diagram of the search and selection process 
Table 1 Summary of papers and findings by country and year

\begin{tabular}{|c|c|c|c|c|c|c|c|c|c|}
\hline $\begin{array}{l}\text { Authors, } \\
\text { Year of Publication }\end{array}$ & Country & $\begin{array}{l}\text { Sample } \\
\text { size }\end{array}$ & $\begin{array}{l}\text { Response } \\
\text { rate }(\%)\end{array}$ & Gender & Professional Group & $\begin{array}{l}\text { Individual and } \\
\text { Workplace Factors }\end{array}$ & $\begin{array}{l}\text { Prevalence } \\
\text { High EE (\%) }\end{array}$ & $\begin{array}{l}\text { Prevalence } \\
\text { High DP (\%) }\end{array}$ & $\begin{array}{l}\text { Prevalence } \\
\text { Low PA (\%) }\end{array}$ \\
\hline 1. Jahrami et al. [42] & Bahrain & 153 & 58.0 & $\begin{array}{l}\text { Males (48.0\%), } \\
\text { females (52.0\%) }\end{array}$ & $\begin{array}{l}\text { Doctors }(9.2 \%), \\
\text { nurses }(78.4 \%), \\
\text { other healthcare } \\
\text { professionals }(12.4 \%)\end{array}$ & Job satisfaction & 24.2 & 18.3 & 28.1 \\
\hline $\begin{array}{l}\text { 2. Mohammed et al. } \\
\text { [28] }\end{array}$ & Egypt & 84 & 64.6 & $\begin{array}{l}\text { Males (54.8\%), } \\
\text { females (45.2\%) }\end{array}$ & Residents & $\begin{array}{l}\text { Working hours } \\
\text { Burnout was } \\
\text { correlated with } \\
\text { different } \\
\text { personality } \\
\text { domains and } \\
\text { working hours }\end{array}$ & 81.0 & 64.3 & 52.4 \\
\hline $\begin{array}{l}\text { 3. Shams and } \\
\text { El-Masry [26] }\end{array}$ & Egypt & 98 & 73.1 & $\begin{array}{l}\text { Males (73.5\%), } \\
\text { females (26.5\%) }\end{array}$ & $\begin{array}{l}\text { Anesthesiologists: } \\
\text { Residents }(30.6 \%), \\
\text { assistant lecturers } \\
(32.7 \%), \\
\text { lecturers }(16.3 \%), \\
\text { assistant professors } \\
(12.2 \%), \\
\text { professors (8.2\%) }\end{array}$ & $\begin{array}{l}\text { Job stress, } \\
\text { working condition, } \\
\text { lack of support }\end{array}$ & 62.2 & 56.1 & 58.2 \\
\hline 4. Khashaba et al. [36] & Egypt & 140 & 100.0 & All males & $\begin{array}{l}\text { Emergency medical } \\
\text { responders }\end{array}$ & $\begin{array}{l}\text { Organizational } \\
\text { stressors }\end{array}$ & 20.0 & 9.3 & 19.3 \\
\hline 5. Hamaideh [24] & Jordan & 181 & 82.3 & $\begin{array}{l}\text { Males }(55.8 \%) \text { and } \\
\text { females }(44.2 \%)\end{array}$ & Nurses & Job satisfaction & 54.7 & 34.2 & 38.7 \\
\hline 6. Ashkar et al.[30] & Lebanon & 155 & 75.0 & $\begin{array}{l}\text { Males }(55.5 \%) \text { and } \\
\text { females }(44.5 \%)\end{array}$ & $\begin{array}{l}\text { Residents } \\
\text { (different specialties) }\end{array}$ & $\begin{array}{l}\text { Coping with stress } \\
\text { at work, number } \\
\text { of on calls }\end{array}$ & 67.7 & 47.1 & 37.4 \\
\hline $\begin{array}{l}\text { 7. Alameddine et al. } \\
\text { [35] }\end{array}$ & Lebanon & 755 & NR & $\begin{array}{l}\text { Males }(49.6 \%) \text { and } \\
\text { females }(50.3 \%) \\
0.1 \% \text { missing }\end{array}$ & $\begin{array}{l}\text { Doctors }(44.8 \%) \text {, } \\
\text { nurses }(32.7 \%) \text {, } \\
\text { allied health in primary } \\
\text { health care and other } \\
\text { health professionals } \\
(22.5 \%)\end{array}$ & $\begin{array}{l}\text { High burnout, } \\
\text { lower level of } \\
\text { education, and } \\
\text { low tenure were } \\
\text { all associated with } \\
\text { increased } \\
\text { likelihood to quit }\end{array}$ & 23.2 & 13.8 & 18.7 \\
\hline 8. Sabbah et al. [25] & Lebanon & 200 & 95.2 & $\begin{array}{l}\text { Males }(31.5 \%) \text { and } \\
\text { females }(68.5 \%)\end{array}$ & Nurses & $\begin{array}{l}\text { Work satisfaction, } \\
\text { work overload, } \\
\text { job title, } \\
\text { shift duty }\end{array}$ & 77.5 & 36.0 & 33.0 \\
\hline 9. Abdallah [40] & Palestine & 180 & NR & $\begin{array}{l}\text { Males }(33.3 \%) \text { and } \\
\text { females }(66.7 \%)\end{array}$ & Social workers & Self esteem & 20.0 & 46.7 & 13.3 \\
\hline $\begin{array}{l}\text { 10. Abushaikha and } \\
\text { Saca-Hazboun [34] }\end{array}$ & Palestine & 152 & 59.6 & $\begin{array}{l}\text { Males }(26.3 \%) \text { and } \\
\text { females }(73.7 \%)\end{array}$ & $\begin{array}{l}\text { Staff nurses }(80.3 \%), \\
\text { head nurses }(12.5 \%), \\
\text { assistant head nurses } \\
(7.2 \%)\end{array}$ & Job satisfaction & 37.5 & 9.2 & 39.5 \\
\hline 11. Alhajjar et al.[41] & Palestine & 176 & 70.4 & $\begin{array}{l}\text { Males }(48.3 \%) \text { and } \\
\text { females }(51.7 \%)\end{array}$ & Social workers & Employer type & 56.2 & 67.0 & 85.8 \\
\hline 12. Sadat-Ali et al. [39] & $\begin{array}{l}\text { Saudi } \\
\text { Arabia }\end{array}$ & 69 & 51.9 & NA & $\begin{array}{l}\text { Orthopedic surgeons } \\
\text { (consultants and } \\
\text { specialists) }\end{array}$ & $\begin{array}{l}\text { Hospital type; } \\
\text { Government }(G) \\
\text { or Private }(P)\end{array}$ & $\begin{array}{l}\text { Overall = } 50.7 \\
G=40.8 \\
P=70.0\end{array}$ & $\begin{array}{l}\text { Overall }=59.4 \\
G=49.0 \\
P=80.0\end{array}$ & $\begin{array}{l}\text { Overall }=17.0 \\
G=14.5 \\
P=30.0\end{array}$ \\
\hline 13. Al-Dardas et al. [23] & $\begin{array}{l}\text { Saudi } \\
\text { Arabia }\end{array}$ & 198 & 79.0 & NA & Nurses & $\begin{array}{l}\text { Nationality, } \\
\text { marital status area } \\
\text { of work and job } \\
\text { duration }\end{array}$ & 45.6 & 42.0 & 28.5 \\
\hline 14. Al Turki [37] & $\begin{array}{l}\text { Saudi } \\
\text { Arabia }\end{array}$ & 37 & 61.6 & All Females & Saudi Nurses & Job duration & 45.9 & 48.6 & 13.6 \\
\hline $\begin{array}{l}\text { 15. Al-Ayoubi and } \\
\text { Jan [22] }\end{array}$ & $\begin{array}{l}\text { Saudi } \\
\text { Arabia }\end{array}$ & 130 & 65.0 & $\begin{array}{l}\text { Males }(45.0 \%) \text { and } \\
\text { females }(55.0 \%)\end{array}$ & $\begin{array}{l}\text { Pediatricians: } \\
\text { consultants, }(46.0 \%), \\
\text { residents }(31.0 \%) \\
\text { assistants }(23.0 \%)\end{array}$ & $\begin{array}{l}\text { Hospital types, } \\
\text { years of practice, } \\
\text { number of clinics } \\
\text { per week }\end{array}$ & \multicolumn{3}{|c|}{$\begin{array}{l}\text { No subscales prevalence } \\
18 \% \text { Normal (MBI score 20-30) } \\
82 \% \text { Abnormal (MBI score >30) } \\
\text { a. } 19 \% \text { Mild (MBI score 31-40) } \\
\text { b. } 29 \% \text { Moderate (MBI score 41-60) } \\
\text { c. 34\% Severe (MBI score 61-80) }\end{array}$} \\
\hline 16. Aldrees et al. [29] & $\begin{array}{l}\text { Saudi } \\
\text { Arabia }\end{array}$ & 348 & 74.0 & $\begin{array}{l}\text { Males }(72.0 \%) \text { and } \\
\text { females }(28.0 \%)\end{array}$ & $\begin{array}{l}\text { Consultants }(54.0 \%) \text {, } \\
\text { residents }(46.0 \%)\end{array}$ & $\begin{array}{l}\text { Number of years } \\
\text { in practice, } \\
\text { worked concurrently } \\
\text { in the private } \\
\text { sectors }\end{array}$ & 54.0 & 35.0 & 33.0 \\
\hline
\end{tabular}


Table 1 Summary of papers and findings by country and year (Continued)

\begin{tabular}{|c|c|c|c|c|c|c|c|c|c|}
\hline 17. Al-Sareai et al. [38] & $\begin{array}{l}\text { Saudi } \\
\text { Arabia }\end{array}$ & 370 & 94.9 & $\begin{array}{l}\text { Males }(81.9 \%) \text { and } \\
\text { females }(18.1 \%)\end{array}$ & $\begin{array}{l}\text { Primary health care } \\
\text { doctors: } \\
\text { residents }(98.1 \%), \\
\text { specialists }(1.4 \%), \\
\text { consultants }(0.5 \%)\end{array}$ & $\begin{array}{l}\text { Number of } \\
\text { working days, } \\
\text { age and nationality }\end{array}$ & 29.5 & 15.7 & 19.7 \\
\hline $\begin{array}{l}\text { 18. Al-Imam and } \\
\text { Al-Sobayel [33] }\end{array}$ & $\begin{array}{l}\text { Saudi } \\
\text { Arabia }\end{array}$ & 119 & 72.4 & $\begin{array}{l}\text { Males (37.0\%) and } \\
\text { females (63.0\%) }\end{array}$ & Physiotherapists & $\begin{array}{l}\text { Workload, control, } \\
\text { reward, fairness, } \\
\text { values }\end{array}$ & 42.0 & 33.6 & 28.5 \\
\hline $\begin{array}{l}\text { 19. Al-Dubai and } \\
\text { Rampal [27] }\end{array}$ & Yemen & 563 & 70.4 & $\begin{array}{l}\text { Males }(59.5 \%) \text { and } \\
\text { females }(40.5 \%)\end{array}$ & $\begin{array}{l}\text { Doctors: } \\
\text { specialists (30.0\%), } \\
\text { non-specialists (70.0\%) }\end{array}$ & $\begin{array}{l}\text { Long working } \\
\text { hours, work-life } \\
\text { balance, dealing } \\
\text { with patients, and } \\
\text { not chewing Khat }\end{array}$ & 63.2 & 19.4 & 33.0 \\
\hline
\end{tabular}

Note DP denotes Depersonalization, EE denotes Emotional Exhaustion, NR denotes Not Reported, PA denotes Personal Accomplishment

occupation of 175 participants was not clearly identified. Almost half (49.3\%) of the study samples were females based on the 17 papers that reported the participants' gender. Out of the 4108 HCP included in the review, approximately one-third $(N=1271 ; 30.9 \%)$ were working in Saudi Arabia from various backgrounds. The nationalities of participants were reported in all papers except the study in Bahrain.

The prevalence of each burnout dimension (EE, DP and PA) was reported in 18 papers while one study only reported the overall prevalence of burnout [22]. A high level of burnout among nurses was reported in three studies from Saudi Arabia, Jordan, and Lebanon, [23-25]. Other studies concluded that burnout levels of general practitioners, residents and specialists were higher compared to other health professions [26]. The burnout prevalence for the three domains ranged from 20.0 to $81.0 \%$ for emotional exhaustion (EE), 9.2 to $80.0 \%$ for depersonalization (DP) and 13.3 to $85.8 \%$ for low personal accomplishment (PA). A study in Yemen reported a significant association between higher burnout levels and younger age group of doctors [27]. Similar findings were found in studies conducted in Egypt, Saudi Arabia, and Lebanon [28-30]. Two papers reported a significant association between female gender and EE [23, 26]. Other factors associated with high burnout included being single and nationality [25-27, 31, 32].

Several studies examined the relationship between burnout and workplace factors. The study from Yemen found a significant association between the prevalence of burnout and working long hours. Specifically, doctors working more than $40 \mathrm{~h}$ per week had a higher level of burnout (OR $=2.1,95 \%$ Confidence Intervals 1.3-3.6, $p<0.01$ ) [27]. Similar findings were reported by a study in Lebanon which found HCP working for more than $80 \mathrm{~h}$ per week, and having more than eight on-calls per month were predictive of burnout in medical residents [30]. Years of practice, work duration, work load, type of the organization, shift rotations and duty times were the most commonly reported factors associated with burnout $[22,25,29]$. Low job satisfaction, a poor reward system, and injustice were also associated with a high level of burnout [24, 33, 34].

\section{Discussion}

The primary aim of this study was to estimate the prevalence of burnout among HCP in Arab countries. Our study findings revealed moderate-to-high but wideranging prevalence estimates of burnout among $\mathrm{HCP}$ in Arab countries. For example, two studies conducted in Lebanon reported high prevalence estimates of $\mathrm{EE}$ among doctors (67.7\%) [30] and nurses (77.5\%) [25]; whereas another study conducted in Lebanon reported a lower prevalence of high EE (23.2\%) among doctors and nurses [35]. However, the prevalence of high DP was reported to be $70.7 \%$ in one study [35] compared to the other two studies $47.1 \%$ [30] and 36.0\% [25]. Similarly, two studies $[26,28]$ conducted on doctors in Egypt reported a high prevalence of high EE $(62.2 \%, 81.0 \%$, respectively), high DP $(56.1 \%, 64.3 \%$, respectively) and low PA (52.4\%, 58.2\%, respectively) compared to a study on emergency medical responders in Egypt that reported a lower prevalence of high scores across all three subscales $(20.0 \%$ EE, 9.3\% DP, 27.0\% PA) [36]. Prevalence for high burnout in Saudi Arabia showed similar variability across doctors, nurses, and physiotherapists with EE ranging from 29.5 to $54.0 \%$, DP from 15.7 to $48.6 \%$, and PA from 17.0 to $71.5 \%$ [23, 29, 37-39]. In agreement with these findings, the prevalence estimates for all three sub-scales for nurses and social workers in Palestine ranged considerably between the three studies [34, 40, 41]. Overall, studies conducted in Bahrain [42] and Jordan [24] reported some of the lowest prevalence estimates of high EE $(24.2 \%, 32.7 \%$, respectively), DP (18.3\%, 27.7\%, respectively), and low PA (26.8\%, 26.8\%, respectively) across all three sub-scales. It is unclear why there were wide-ranging estimates for burnout both within- and between-countries. However, organizational (e.g., organizational climate, management/leadership styles, horizontal and vertical communication) and/or individual factors (e.g., demographic characteristics, personality characteristics, individual attitudes, maladaptive 
coping styles) that differ across health systems, health care facilities, and HCP within- and betweencountries may be responsible. Future work should focus on elucidating the organizational and individual factors that are associated with burnout in $\mathrm{HCP}$ working in Arab countries. Finally, there was considerable methodological and statistical heterogeneity between studies and this may account for a portion of the variability in burnout prevalence estimates.

Only one study [23] mentioned whether the study sample was composed of nationals or expatriate HCP and this is particularly important for the Gulf countries, such as Bahrain, Kuwait, Qatar, Saudi Arabia, and the United Arab Emirates that have large multinational expatriate HCP populations. The study found that non-Saudi Arabian nurses were significantly more prone to high EE than Saudi Arabian nurses (27.3\% \pm $12.1 \%$ versus $21.6 \% \pm 2.9 \% ; p<0.01$ ), whereas there were no significant differences between the prevalence estimates of high DP and low PA [23]. Two crosssectional studies conducted in Kuwait [31] and Qatar [43] were not included in this review as they did not provide the prevalence of burnout (Kuwait) or utilize the standardized MBI to assess burnout (Qatar). The study in Kuwait randomly selected two out of five health regions (Capital and Farwaniya) and sent the MBI questionnaire to all 378 physicians working in primary healthcare and family centers in these areas and 200 physicians (44.0\% male; $49.0 \%$ Kuwaiti national) completed the MBI (52.9\% response rate). Males, non-Kuwaitis, aged more than 40 years, working for more than 10 years, holding only a bachelor degree, with no hobby, and suffering from at least one chronic disease were personal factors significantly related to emotional exhaustion. Non-Kuwaiti national general practitioners working in the Farwaniya area were more likely to suffer from depersonalization. However, higher-income, specialist Kuwaiti physicians that were married and with a hobby, working in the Capital health area were factors associated with higher personal accomplishment [31]. Similarly, a cross-sectional survey was conducted among general practitioners working in 21 primary healthcare centers in Qatar using the Astudillo and Mendinueta questionnaire; scores ranged from 0 to 48 ; burnout $=$ score 219) [43]. One-hundred and eighty-three general practitioners (50.8\% male; 20.2\% Qatari) responded (79.5\% response rate) and $12.6 \%$ were classified as burned out with the prevalence of burnout significantly greater among females $(28.1 \%)$ compared to males (6.9\%), and also Qatari nationals (37.8\%) compared to expatriates (11.6\%) [44]. Both of these studies suggest that there may be a relationship between citizenship, or at least the personal and workplace factors associated with permanent residence, and burnout. Currently, there is a lack of research exploring the factors associated with burnout amongst expatriates versus nationals in Gulf countries; however, perceived stability of employment/residence and isolation from family in their home country may partly explain the higher prevalence of burnout amongst expatriate $\mathrm{HCP}$ working in Arab countries. Future research is needed to validate these suggestions.

The category of HCP and the types of departments and specialties were not specified in all papers. However, we were able to categorize the participants from all selected papers into three main types: studies that assessed a mixed group of HCP that worked in a specific institution or department; studies that assessed a specific group of HCP that worked in different departments; and studies that assessed a specific group of HCP who worked in a specific department and a specific specialty. A few studies assessed one category of HCP such as physiotherapists, mental health workers, orthopedic surgeons, anesthesiologists, pediatricians, and non-medical emergency responders while the rest included a mixed group of HCP that included nurses and doctors and other allied health care professionals that were not categorized in some of the studies. Twelve studies concluded that physicians and residents were suffering from higher burnout than reported international prevalence estimates with some differences depending on the specialty and the nationality. There were only three studies included in this review that assessed specialist physicians. Orthopedic surgeons in Saudi Arabia were found to have a similar prevalence of burnout as pediatricians [22]. The same study demonstrated that age, gender, and setting of work were significantly associated with burnout levels. Similar findings were found in a study which reported that $70 \%$ of physicians from different specialties had high burnout levels [29]. Higher levels of burnout were found among obstetrics and gynecology, family medicine, anesthesia, intensive care, internal medicine, and cardiology specialties. Moreover, a study conducted among anesthesiologists found that $62.2 \%$ of the subjects experienced high EE, $56.1 \%$ had high DP, and 58.2\% low PA [26]. The high prevalence of burnout amongst these specialties may be due to higher case load and/or complex cases. Residents were categorized in some of the studies and were found to have high levels of burnout with the highest prevalence in the EE domain followed by DP and then low PA [28-30]. The study among residents in Egypt concluded that residents were potentially more prone to higher burnout levels due to the high demands placed upon them, long working hours, insufficient income, a perceived mismatch between effort 
and reward, and poor hospital administration [28]. Studies exploring the level of burnout among nurses only reported moderate to high prevalence estimates across all three subscales suggesting that this group of HCP may also be at a higher risk of burnout [23$25,34]$

Although most studies focused on doctors and nurses, there were several studies that evaluated burnout among other HCP; including social workers, physiotherapists, occupational therapists, and mental health workers. Two studies assessed burnout levels in a representative sample of social workers in the West Bank and Gaza, Palestine [40, 41]. Both studies showed that social workers had high burnout levels across different subdomains; however, the overall prevalence of burnout was higher in social workers in Gaza than compared to the West Bank (high EE 56.2 vs. 20.0\%, high DP 67.0 vs. $46.7 \%$, low PA 85.8 vs. $53.3 \%$; respectively) [40, 41]. Currently, there is a lack of research focusing on burnout in $\mathrm{HCP}$ in the Palestine territories and the difference in burnout prevalence between social workers in Gaza compared to the West Bank may be due to the unique political, social, and cultural conditions of these areas. In other occupations within healthcare settings, moderate levels of high burnout were reported for emergency medical responders in Egypt (EE 20.0\%, DP 9.3\%, PA 27.0\%) [36]. A recent paper in Saudi Arabia also reported a moderate level of burnout among physiotherapists with high EE in $42.0 \%$ of participants and $39.4 \%$ of participants had a moderate level of DP while $37.8 \%$ of the subjects showed low PA [33]. Future burnout research in Arab countries may want to consider including the wider spectrum of HCP including dentists, dieticians, medical technicians and laboratory scientists, midwives, pharmacists, and radiographers.

The prevalence estimates reported in this study are comparable to the prevalence in non-Arabic speaking countries such as Canada, France, United Kingdom, and the United States. Results of burnout in all three dimensions were congruent and in some studies exceeded levels of self-reported burnout in studies conducted in westernized and/or developed countries such as Belgium [44] (hospital nurses 75\% high EE), England [45] (mental health nurses 52\% high EE, 38\% high DP, 60\% low PA), Japan [46] (psychiatrists 21\% high EE, 12\% high DP, 72\% low PA), Poland [47] (hospital nurses 71\% EE, 40\% DP, 77\% low PA), Scotland [48] (psychiatric nurses 27\% high EE, 7\% high DP, 33\% low PA), the United States [49], and Wales [50] (community mental health nurses 36\% high $\mathrm{EE}, 12 \%$ high DP, $10 \%$ low PA). However, selfreported burnout amongst nurses in Australia [50, 51] (mental health psychiatric nurses 36\% high EE, 24\% high DP, 23\% low PA, forensic psychiatric nurses 22\% high EE, 17\% high DP, 20\% low PA [51]; rural psychiatric nurses [52] 10\% high EE, 12\% high DP, 12\% low PA) and Finland [53] (mental health and psychiatric nurses 29\% high EE, 21\% high DP, 16\% low PA), were lower than other westernized developed countries and also compared to the estimates from Arab countries. Interestingly, burnout estimates for hospital nurses working in Iran, a Muslim Persian country, were lower than nurses working in Muslim Arab countries (23\% high EE, 5\% high DP, 21\% low PA) [54]. At present, there is a dearth of research directly comparing the prevalence of burnout between Arab Muslim countries such as in the Arabian Gulf and neighboring Persian Muslim country Iran. The Iranian sample of nurses $(N=180)$ working in public hospitals in Shiraz were all graduates of either technological educational institutions (67\%) or universities (33\%) and the majority of nurses were married (73.9\%) with $0-6$ children and a mean $( \pm$ SD) work experience of $2.8 \pm 1.4$ years. The Iranian sample may have contained nurses that were older, more educated/trained, and with a greater number of years of nursing experience. These factors may account for the lower levels of burnout in the Iranian nurses.

The second aim of this review was to explore the various personal, interpersonal, and organizational factors that may be associated with burnout in HCP. Among 210 Lebanese nurses who worked in different hospitals and departments, high EE was higher among nurses aged 30-39 years and among married nurses who had higher EE, DP was highest among nurses in the private sector, and low PA was highest among nurses in the public sector [25]. In addition, DP was higher among nurses who worked night and rotating shifts [25]. In Jordan, a study found that $54.7 \%$ of mental health nurses $(N=181)$ had a high level of EE [24]. The author also reported that low PA was found to be higher in older Jordanian nurses, those who do not intend to leave their job, and nurses with longer psychiatric experience. The study suggested that the high levels of burnout among these HCP were associated with a poor psychosocial work environment, low social support from colleagues and supervisors, or by working with difficult and uncooperative patients with a poor prognosis. These findings were similar to those of the study in Bahrain which demonstrated that psychiatric $\mathrm{HCP}$ in a hospital, majority were nurses, had high burnout levels comparable with other studies that assessed staff in mental health institutions [42]. Most of the studies suggested that general workplace and organizational factors were associated with HCP burnout; however, there was variability in the associations between the proposed factors and burnout. Two studies did not find an association between supervision or lack of control/decision making and burnout [30,36]; while two other studies reported a negative correlation between low social support from colleagues and 
supervisors with high burnout among nurses and anesthesiologists [24, 26]. A study conducted among 755 primary health care providers in Lebanon reported that respondents with a high level of burnout on the PA subscale had 3.05 times the odds of quitting their jobs [35]. The study also found that an increase in the number of work hours per week and full-time employment status were associated with reduced likelihood to quit [35]. Burnout among Saudi Arabian physiotherapists was associated with some factors such as years of experience and age, role, and workload [33]. Specifically, there was an inverse relationship between DP and perceived reward and fairness; and a positive relationship between workload and EE [33]. Interestingly, a recent crosssectional study conducted in Saudi Arabia assessed the prevalence of burnout (October to December 2014) amongst a convenient sample of Saudi Arabian nationals working as critical care nurses $(N=150)$ in three government-run general hospitals in Hail and reported a significant negative relationship between $\mathrm{EE}$ and job satisfaction [55]. This finding may have important implications for staff turnover as job satisfaction may strongly influence an individual's intention to leave a healthcare organization or profession [56]. Future studies exploring the prevalence of burnout in HCP working in Arab countries should endeavor to collect information on job satisfaction and intention to leave using standardized measures. Such data would enable researchers to explore the relationships between burnout, job satisfaction, and intention to leave.

\section{Limitations}

The main study limitations include the low number of studies that have been conducted among HCP in Arab countries and the poor quality and reporting of methodology and results in the majority of papers. As such, intra- and inter-country comparisons of burnout prevalence were limited by methodological differences such as sampling, recruitment, data collection, and analysis. Future studies assessing the prevalence of burnout among $\mathrm{HCP}$ in Arabic populations using standardized methodologies are needed. A few studies explored the association between various personal, workplace, and other environmental factors and the three domains of burnout; however, the majority of these studies did not use multivariate techniques and so the results need to be interpreted with caution. Future studies should attempt to collect additional data on factors that may be associated with burnout, such as marital status, years of clinical experience, place of work, location, specialty, shift pattern, perceived support from supervisors and support from co-workers, and self-rated job strain. Our search strategy involved conducting independent searches on six different electronic databases for papers published in English or Arabic between January 1980 and November 2014; and searching the PHAW database and contact list to retrieve unpublished papers or papers not published in indexed journals. Despite these efforts, it is possible that papers meeting our inclusion criteria were missed and therefore, not included in the review.

\section{Conclusion}

In view of the ongoing changes in the economic, social, and political environment in the majority of Arab countries, further studies are needed to identify the factors that are leading to the high level of burnout among HCP in the Arab world. This systematic review reinforces the need to reduce occupational stressors by improving the workplace environment and developing culturallyrelevant resilience building programs for HCP working in Arab countries. The burnout literature would benefit from more high-quality studies with larger samples that identify HCP by occupation/specialty and other risk factors related to burnout such as age, personal factors, workplace factors, and other environmental factors. Future studies assessing the prevalence of burnout among $\mathrm{HCP}$ in Arab populations may want to consider standardizing the study methodology to compare within- and between-country estimates of burnout prevalence. Further studies are needed to assess burnout among specific $\mathrm{HCP}$ and to determine the profile of HCP that are usually at-risk of burnout. Identifying those at risk will help practitioners develop coping and wellness programs that might alleviate some of the factors that lead to stress and burnout in HCP. Future studies using longitudinal designs would allow researchers to explore the causal risk factors and assess whether self-reported burnout fluctuates over time.

This systematic review shows moderate-to-high estimates of self-reported burnout among HCP in Arab countries that are similar to prevalence estimates in non-Arabic speaking westernized developed countries. Specific occupations and specialties appear to be at a higher risk of burnout and the type of work, duration, workload, and other personal factors seem to be associated with burnout level. Many studies did not measure or report the organizational and workplace factors potentially associated with burnout; therefore, future studies need to assess and report all important factors.

\section{Additional file}

Additional file 1: Literature Search Details. Literature Search Syntax for PubMed. (DOCX 23 kb)

\section{Abbreviations}

DP: Depersonalization; EE: Emotional exhaustion; HCP: Healthcare professionals; MBI: Maslach Burnout Inventory; PA: Personal accomplishment; PHAW: Public Health in the Arab World; PRISMA: Preferred Reporting Items 
for Systematic reviews and Meta-Analyses; STROBE: STrengthening the Reporting of OBservational studies in Epidemiology; WHO-EMRO: World Health Organization-Regional Office for the Eastern Mediterranean

\section{Acknowledgements}

Not applicable.

\section{Funding}

The authors received no financial support for the research, authorship, and/ or publication of this article.

\section{Availability of data and materials}

See Additional file 1

\section{Authors' contributions}

IE conceived the idea. IE, AE, SY and TL developed the protocol and IE, AE and SY conducted the literature search for articles. IE, AE and SY reviewed the articles and conducted the quality assessment. All authors were involved in the review and interpretation of the study findings. IE drafted the manuscript and AE and TL revised the manuscript. All authors have critically reviewed, provided intellectual input to the manuscript and approved the final version of the manuscript.

\section{Competing interests}

The authors declare that they have no competing interests.

\section{Consent to publication}

Not applicable

\section{Ethical approval and consent to participate}

No ethical approval was required as the systematic review is based on published data.

\section{Publisher's Note}

Springer Nature remains neutral with regard to jurisdictional claims in published maps and institutional affiliations.

\section{Author details}

'Institute of Public Health, College of Medicine and Health Sciences, United Arab Emirates University, Al Ain, PO Box 17666, United Arab Emirates. ${ }^{2}$ Department of Psychiatry and Behavioral Science, College of Medicine and Health Sciences, United Arab Emirates University, Al Ain, PO Box 17666, United Arab Emirates.

Received: 26 May 2016 Accepted: 18 May 2017

Published online: 17 July 2017

\section{References}

1. Felton JS. Burnout as a clinical entity-its importance in health care workers. Occup Med (Lond). 1998;48(4):237-50

2. Maslach C, Schaufeli WB, Leiter MP. Job burnout. Annu Rev Psychol. 2001:52:397-422

3. Schaufeli WB, Greenglass ER. Introduction to special issue on burnout and health. Psychol Health. 2001;16(5):501-10.

4. Cordes CL, Dougherty TW. A review and an integration of research on job burnout. Acad Manag. 1993;18(4):621.

5. Aiken LH, Clarke SP, Sloane DM, Sochalski J, Silber JH. Hospital nurse staffing and patient mortality, nurse burnout, and job dissatisfaction. JAMA. 2002: 288(16):1987-93.

6. Gundersen L. Physician burnout. Ann Intern Med. 2001;135(2):145-8.

7. Parker PA, Kulik JA. Burnout, self- and supervisor-rated job performance, and absenteeism among nurses. J Behav Med. 1995;18(6):581-99.

8. Shanafelt TD, Bradley KA, Wipf JE, Back AL. Burnout and self-reported patient care in an internal medicine residency program. Ann Intern Med. 2002:136(5):358-67.

9. Trufelli DC, Bensi CG, Garcia JB, et al. Burnout in cancer professionals: a systematic review and meta-analysis. Eur J Cancer Care (Engl). 2008;17(6):524-31.

10. Dewa CS, Loong D, Bonato S, Thanh NX, Jacobs P. How does burnout affect physician productivity? A systematic literature review. BMC Health Serv Res. 2014;14:325
11. Epp K. Burnout in critical care nurses: a literature review. Dynamics. 2012; 23(4):25-31.

12. Khamisa N, Peltzer K, Oldenburg B. Burnout in relation to specific contributing factors and health outcomes among nurses: a systematic review. Int J Environ Res Public Health. 2013;10(6):2214-40.

13. Rama-Maceiras $P$, Jokinen J, Kranke P. Stress and burnout in anaesthesia: a real world problem? Curr Opin Anaesthesiol. 2015;28(2):151-8.

14. Roberts DL, Cannon KJ, Wellik KE, Wu Q, Budavari Al. Burnout in inpatientbased versus outpatient-based physicians: a systematic review and metaanalysis. J Hosp Med. 2013;8(11):653-64.

15. Toh SG, Ang E, Devi MK. Systematic review on the relationship between the nursing shortage and job satisfaction, stress and burnout levels among nurses in oncology/haematology settings. Int J Evid Based Healthcare. 2012;10(2):126-41.

16. Hätinger B. The League of Arab States. Norderstedt: GRIN Verlag; 2009.

17. Al-Abbadi I. Improving Equity of Access to Pharmaceutical Therapies in Europe, Middle East \& Africa. Athens: Paper presented at: ISPR 11th Annual European Congress; 2008.

18. Moher D, Liberati A, Tetzlaff J, Altman DG. Preferred Reporting Items for Systematic Reviews and Meta-Analyses: The PRISMA Statement. J Clin Epidemiol. 2009;62(10):1006-12.

19. Von Elm E, Altman DG, Egger M, Pocock SJ, Gøtzsche PC, Vandenbroucke JP. STROBE Initiative. The Strengthening the Reporting of Observational Studies in Epidemiology (STROBE) Statement: Guidelines for reporting observational studies. J Clin Epidemiol. 2008;61(4):344-9.

20. Schaufeli WB, Enzmann D. The Burnout Companion to Study and Practice: A Critical Analysis. London: Taylor and Francis; 1998.

21. Maslach C, Jackson SE. The measurement of experiences burnout. J Occup Behav. 1981:2:99-113.

22. Al-Youbi RA, Jan MM. Burnout syndrome in pediatric practice. Oman Med J. 2013:28(4):252-4

23. Al-Dardas H, Al-Enizi N, Al-Gazal M, Al-Maghrabi G, Al-Turki H, Al-Turki R. Burnout syndrome among multinational nurses working in Saudi Arabia. Ann Afr Med. 2010;9(4):226-9.

24. Hamaideh SH. Burnout, social support, and job satisfaction among Jordanian mental health nurses. Issues Ment Health Nurs. 2011;32(4):234-42.

25. Sabbah IH, Sabbah H, Sabbah S, Akoum H, Droubi N. Burnout among Lebanese nurses: Psychometric properties of the Maslach Burnout Inventory-Human Services Survey (MBI-HSS). Health. 2012:4(9):644-52.

26. Shams T, El-Masry R. Job Stress and Burnout among Academic Career Anaesthesiologists at an Egyptian University Hospital. Sultan Qaboos Univ Med J. 2013;13(2):287-95.

27. Al-Dubai SA, Rampal KG. Prevalence and associated factors of burnout among doctors in Yemen. J Occup Health. 2010;52(1):58-65.

28. Mohammed KA, Ali EG, Youssef IM, Fahmy MT, Haggag WE. Burnout and Personality among Egyptian Residents. Arab J Psychiatry. 2013;24(2):148-60.

29. Aldrees TM, Aleissa S, Zamakhshary M, Badri M, Sadat-Ali M. Physician wellbeing: prevalence of burnout and associated risk factors in a tertiary hospital, Riyadh, Saudi Arabia. Ann Saudi Med. 2013;33(5):451-6.

30. Ashkar K, Romani M, Musharrafieh U, Chaaya M. Prevalence of burnout syndrome among medical residents: experience of a developing country. Postgrad Med J. 2010;86(1015):266-71.

31. Abdulghafour YA, Bo-hamra AM, Al-Randi MS, Kamel MI, El-Shazly MK Burnout syndrome among physicians working in primary health care centers in Kuwait. Alexandria J Med. 2011:47(4):351-7.

32. Al-Shoraian GMJ, Hussain N, Alajmi MF, Kamel MI, El-Shazly MK. Burnout among family and general practitioners. Alexandria J Med. 2011:47:359-64.

33. Al-Imam DM, Al-Sobayel HI. The Prevalence and Severity of Burnout among Physiotherapists in an Arabian Setting and the Influence of Organizational Factors: An Observational Study. J Phys Ther Sci. 2014;26(8):1193-8.

34. Abushaikha L, Saca-Hazboun H. Job satisfaction and burnout among Palestinian nurses. East Mediterr Health J. 2009;15(1):190-7.

35. Alameddine M, Saleh S, El-Jardali F, Dimassi H, Mourad $Y$. The retention of health human resources in primary healthcare centers in Lebanon: a national survey. BMC Health Serv Res. 2012;12:419.

36. Khashaba EO, El-Sherif MA, Ibrahim AA, Neatmatallah MA. Work-Related Psychosocial Hazards Among Emergency Medical Responders (EMRs) in Mansoura City. Indian J Community Med. 2014;39(2):103-10.

37. Al-Turki HA Saudi Arabian Nurses. Are they prone to burnout syndrome? Saudi Med J. 2010;31(3):313-6. 
38. Al-Sareai NS, Al-Khaldi YM, Mostafa OA, Abdel-Fattah MM. Magnitude and risk factors for burnout among primary health care physicians in Asir Province, Saudi Arabia. East Mediterr Health J. 2013;19(5):426-34.

39. Sadat-Ali M, Al-Habdan IM, Al-Dakheel DA, Shriyan D. Are orthopedic surgeons prone to burnout? Saudi Med J. 2005;26(8):1180-2.

40. Abdallah T. Prevalence and predictors of burnout among Palestinian social workers. Int Soc Work. 2009;52:223-33.

41. Alhajjar B, Alhajjar M, Alhajjar E. Burnout and Self Esteem among Social Workers in Gaza - Palestine. J Alazhar Uni Ghaza. 2012;14(1):21-34.

42. Jahrami HA, Thomas Z, Saif F, et al. The relationship between burnout and job satisfaction among mental health workers in the psychiatric hospital. Bahrain. Arab J Psychiatry. 2013;24(1):69-76.

43. Abdulla L-Q, DMAI-Kuwari MG. Prevalence and determinants of burnout syndrome among primary healthcare physicians in Qatar. S Afr Fam Pract. 2011:53(4):380-3.

44. Stordeur S, D'Hoore W, Vandenberghe C. Leadership, organizational stress, and emotional exhaustion among hospital nursing staff. J Adv Nurs. 2001; 35(4):533-42.

45. Jenkins R, Elliott P. Stressors, burnout and social support: nurses in acute mental health settings. J Adv Nurs. 2004;48(6):622-31.

46. Umene-Nakano W, Kato TA, Kikuchi S, et al. Nationwide survey of work environment, work-life balance and burnout among psychiatrists in Japan PLoS One. 2013;8(2):e55189.

47. Jaracz K, Gorna K, Konieczna J. Burnout, stress and styles of coping among hospital nurses. Rocz Akad Med Bialymst. 2005;50 Suppl 1:216-9.

48. Kilfedder CJ, Power KG, Wells TJ. Burnout in psychiatric nursing. J Adv Nurs. 2001;34(3):383-96.

49. Hanrahan NP, Aiken LH, McClaine L, Hanlon AL. Relationship between psychiatric nurse work environments and nurse burnout in acute care general hospitals. Issues Ment Health Nurs. 2010;31(3):198-207.

50. Edwards D, Burnard P, Hannigan B, et al. Clinical supervision and burnout: the influence of clinical supervision for community mental health nurses. J Clin Nurs. 2006:15(8):1007-15.

51. Happell B, Pinikahana J, Martin T. Stress and burnout in forensic psychiatric nursing. Stress Health. 2003;19(2):63-8.

52. Pinikahana J, Happell B. Stress, burnout and job satisfaction in rural psychiatric nurses: a Victorian study. Aust J Rural Health. 2004:12(3):120-5.

53. Hyrkas K. Clinical supervision, burnout, and job satisfaction among mental health and psychiatric nurses in Finland. Issues Ment Health Nurs. 2005: 26(5):531-56.

54. Sahraian A, Fazelzadeh A, Mehdizadeh AR, Toobaee SH. Burnout in hospital nurses: a comparison of internal, surgery, psychiatry and burns wards. Int Nurs Rev. 2008;55(1):62-7.

55. Alharbi J, Wilson R, Woods C, Usher K. The factors influencing burnout and job satisfaction among critical care nurses: a study of Saudi critical care nurses. J Nursing Manag. 2016;24:708-17.

56. Al-Omar BA. Sources of work-stress among hospital staff at the Saudi MOH. Econ Admin. 2003;17(1):3-16.

\section{Submit your next manuscript to BioMed Central and we will help you at every step:}

- We accept pre-submission inquiries

- Our selector tool helps you to find the most relevant journal

- We provide round the clock customer support

- Convenient online submission

- Thorough peer review

- Inclusion in PubMed and all major indexing services

- Maximum visibility for your research

Submit your manuscript at www.biomedcentral.com/submit
Biomed Central 